\title{
Erratum to: Ovarian Tumours in Children
}

David Drake and Sarah Creighton

\section{Erratum to: \\ Chapter 24 in: D.J. Ledbetter and P.R.V. Johnson (eds.), Endocrine Surgery in Children, https://doi.org/10.1007/978-3-662-54256-9_24}

The book was originally published with the incorrect author for chapter 24 . The chapter authors were David Drake and Sarah Creighton, not David Thomas. We have revised the chapter to reflect this as well as to add their affiliations.

The updated online version of this chapter can be found at https://doi.org/10.1007/978-3-662-54256-9_24 